\title{
Validitas dan Praktikalitas Modul Laju Reaksi Terintegrasi Eksperimen dan Keterampilan Proses Sains untuk Pembelajaran Kimia di SMA
}

\author{
Andromeda ${ }^{1)}$, Ellizar $^{2)}$, Iryani $^{3)}$, Bayharti $^{4)}$, Yofita Yulmasari ${ }^{5)}$ \\ ${ }^{1,2,3,4)}$ Staf pengajar jurusan kimia FMIPA Universitas Negeri Padang \\ ${ }^{5)}$ Alumni Prodi Pendidikan Kimia FMIPA Universitas Negeri Padang \\ opetsaidir@gmail.com
}

\begin{abstract}
Modules are one of the learning materials that can be used in the learning process. Modules compiled based on guided inquiry learning syntax and integrating experimental activities that will be able to improve students' science process skills. This study aimed to produce a reaction rate module based on guided inquiry integrated experiments and valid student science process skills and practical use in senior high school chemistry learning. The type of this research was research and development $(R \& D)$ and the development model used was the 4-D model which consists of four stages: (1) define, (2) design, (3) development, (4) desseminate. This research was limited to the validity and practicality test. The validity test was carried out by 5 experts and limited trials to reveal the practicality done at SMAN 1 Lubuk Basung. The research instrument used was in the form of a validity and practicality questionnaire which was analyzed using kappa moment $(k)$ Data analysis showed that the average moment of kappa validity was 0.84 with a very high validity category. The average practical kappa moments from teachers and students were respectively 0.83 and 0.85 with a very high practicality category. These results were also supported by the analysis of students' answers in answering critical questions, exercises, prelab questions, postlab questions, and worksheets in modules, with an average value of 90.2. Based on the results of the study it can be concluded that the guided inquiry integrates experiments and science process skills on based reaction rate topic are valid and practical used for chemistry learning in senior high school.
\end{abstract}

Keywords :guided inquiry, science process skills, reactions rate, modules, 4-D models

(c) (i) This is an open access article distributed under the Creative Commons 4.0 Attribution License, which permits unrestricted use, distribution, and reproduction in any medium, provided the original work is properly cited. $\odot 2018$ by author and Universitas Negeri Padang.

\section{PENDAHULUAN}

Pada hakikatnya IPA dibangun atas dasar produk ilmiah, proses ilmiah, dan sikap ilmiah (Carin A.,1997). IPA juga dipandang sebagai proses, produk dan prosedur. Sebagai proses diartikan sebagai kegiatan ilmiah untuk menemukan pengetahuan baru. Sebagai produk diartikan sebagai hasil proses, berupa pengetahuan. Sebagai prosedur diartikan sebagai metodologi untuk mengetahui sesuatu yang disebut dengan metode ilmiah. Semakin jelas bahwa proses pembelajarn IPA lebih ditekankan pada pendekatan keterampilan proses, Siswa dapat menemukan fakta, konsep, dan teori. Hal ini dapat berpengaruh positif terhadap kualitas proses pendidikan maupun produk pendidikan (Trianto, 2010).

Kimia merupakan salah satu disiplin ilmu IPA yang dipelajari di SMA. Kimia mempelajari segala sesuatu tentang zat, yang meliputi komposisi, struktur dan sifat, perubahan, dinamika dan energetika zat yang melibatkan keterampilan dan penalaran (Chang R., 2010). Dapat disimpulkan bahwa dalam mempelajari ilmu kimia peserta didik tidak hanya dituntut untuk mempelajari konsep-konsep dan prinsip-prinsip sains secara verbalistis, hafalan, pengenalan rumus-rumus, dan pengenalan istilah-istilah melalui serangkaian latihan secara verbal namun juga dituntut untuk memiliki pengalaman langsung melalui proses eksperimen agar terwujud pembelajaran yang menekankan pada penerapan keterampilan proses sains (Permendiknas No. 59: 2014).

Keterampila proses sains merupakan pengembangan keterampilan-keterampilan intelektual, sosial, dan fisik yang bersumber dari kemampuan-kemampuan mendasar yang pada prinsipnya adalah dalam diri siswa (Tawil. $\mathrm{M}$ dan Liliasari, 2014). Keterampilan proses sains ini sangat penting bagi setiap siswa sebagai bekal untuk menggunakan metoda ilmiah dalammengembangkan sains untuk memperoleh pengetahuan baru atau mengembangkan pengetahuan 
yang dimilikinya (Mardona, 2013). Keterampilan proses sains menuntut siswa untuk terlibat secara langsung dalam pembelajaran sehingga siswa dapat menemukan sendiri fakta atau konsep yang nantinya akan dapat bertahan lama di ingatan siswa.

Menurut Kurikulum 2013, pembelajaran harus berbasis aktivitas dengan karakteristik interaktif dan inspiratif, kontekstual dan kolaboratif, serta memotivasi peserta didik untuk berpartisipasi aktif dan memberikan ruang yang cukup bagi kreativitas dan kemandirian pesertadidik (Permendiknas No. 103, 2014). Untukmemenuhi tuntutan tersebut, pemerintah melakukan perubahan dalam metode pembelajaran, yaitu pembelajaran yang berdasarkan pada pendekatan saintifik. Pendekatan saintifik merupakanpendekatan yang mendorong siswa lebih aktif melalui kegiatan 5M (mengamati, menanya, mengumpulkan data, mengasosiasi danmengkomunikasikan).

Materi laju reaksi merupakan salah satumateri kimia yang diajarkan di kelas XI (Kurikulum Nasional 2013 revisi 2017). Dalam mempelajari laju reaksi, siswa tidak hanya dituntut untuk mampu menghitung dan menghafal informasi, akan tetapi dalam materi ini siswa dituntut untuk memahami konsep-konsep yang berkaitan erat dengan laju reaksi dengan pengalaman langsung melalui kegiatan eksperimen yang menuntut keterampilan proses sehinggapembelajaran menjadi lebih mudah, bermakna dan diminati. Beberapa penelitian menunjukkan bahwa pengalaman laboratorium/ eksperimen dapat menghasilkan pembelajaran bermakna tidak mudah dilupakan sehingga mendukung pencapaian tujuan pendidikan (Hofstein, A and Lunetta V.N., 2003; Hofstein dan MamlokNaaman, 2007)

Berdasarkan hasil wawancara, dan hasil angket yang diberikan kepada beberapa guru dan siswa di beberapa SMA di Lubuk Basung ditemukan bahwa pembelajaran berbasis laboratorium belum terlaksana secara optimal. Jikapun ada kegiatan eksperimen lebih banyak dilakukan setelah pembelajaran teori di kelas sehingga bersifat mengkonfirmasi konsep. Bahan ajar yang tersedia belum mendukung sepenuhnya penemuan konsep dan belum tersedianya bahan ajar modul yang meng integrasikan eksperimen dalam pembelajaran teori.

Modul merupakan salah satu bahan ajar yang dapat memotivasi siswa untuk belajar secara mandiri maupun kelompok dan dapat membantu siswa dalam menemukan konsep. sesuai tuntutan kurikulum 2013.

Pada kurikulum 2013 model pembelajaran guided inquiry merupakan salah satu model pembelahjaran yang disarankan. Dengan mengintegrasikan sintak model pembelajaran guided inquiry dan kegiatan eksperiman pada modul dapat membantu guru dalam proses pembelajaran. Untuk memenuhi kebutuan ini dilakukan pengembangan modul pembelajaran guided inquiry terintegrasi eksperimen.

Kegiatan belajar yang menerapkan guided inquiry terdiri dari 5 tahap yaitu orientasi, eksplorasi, pembentukan konsep, aplikasi dan penutup (Hanson, 2005). Tahap orientasi merupakan tahap untuk menghubungkan pengetahuan yang akan dipelajari dengan pengetahuan sebelumnya. Kemudian pada tahap eksplorasi, peserta didik memiliki kesempatan untuk melakukan pengamatan, bertanya, mengusulkan, dan menganalisis data atau informasi melalui percobaan/praktikum atau melalui suatu model berupa gambar, grafik, atau tabel data.

Pada tahap pembentukan konsep peserta didik dibimbing dengan pertanyaan kritis (critical thinking question). Setelah itu diperkuat dan diperluas melalui latihan dan soal dalam tahap aplikasi. Setelah keempat tahap tersebut selesai, peserta didik membuat kesimpulan, merenungkan apa yang mereka dapatkan pada tahap penutup. Komponen-komponen pada kegiatan eksperimen sesuai components of the laboratory investigation dari The College Board (2012) meliputi: Concept Invention, Application, Exploration (The Colladge Board, 2012).

Beberapa penelitian menunjukkan bahwa modul berbasis inkuiri terbimbing efektif dalam meningkatkan keterampilan proses sains peserta didik (Sodikun, 2015). Inkuiri terbimbing juga akan mendorong siswa memiliki keterampilan yang baik dan memberikan kesempatan kepada siswa untuk menggunakan berbagai sumber informasi dan ide dalam memahami serta menyelesaikan berbagai permasalahan (Nworgu dan Otum, 2013) Andromeda dkk, (2016) juga menyimpulkan bahwa pembelajaran dengan kegiatan praktikum terintegrasi efektif dalam meningkatkan prestasi belajar siswa.

Beberapa penelitian pengembangan bahan ajar berbasis guided inquiry telah berhasil dilakukan dan disimpulkan bahwa bahan ajar yang dikembangkan valid dan praktis digunakan dalam pembelajaran kimia di SMA/MA 
(Andromeda dkk, 2014; Andromeda dkk, 2015; Andromeda dkk, 2017: Andromeda dkk., 2018).

Berdasarkan kebutuhan akan pentingnya bahan ajar yang berorientasi proses penemuan konsep sesuai tuntutan kurikulum Nasional 2013 revisi 2017, maka dilakukan penelitian pengembangan bahan ajar modul. Penelitian ini bertujuan untuk menghasilkan modul kimia laju reaksi berbasis guided inquiry terintegrasi eksperimen dan keterampilan proses sains siswa yang valid dan praktis digunakan dalam proses pembelajaran kimia di SMA/MA

\section{METODE PENELITIAN}

Jenis penelitian adalah Research and Development $(\mathrm{R} \& \mathrm{D})$. Model pengembangan yang digunakan adalah Four $D$ models, yang terdiri dari 4 tahap yaitu: (1) define, (2) design, (3) Develop, (4) dessiminate. Penelitian ini dibatasi sampai uji validitas dan praktikalitas produk. Uji validitas dilakukan oleh 5 orang expertdan uji coba terbatas untuk praktikalitas di lakukan pada 32 orang peserta didik kelas XI IPA 1 SMAN 1 Lubuk Basung. Objek penelitian ini adalah modul laju reaksi berbasis guided inquiry terintegrasi eksperimen dan keterampilan proses sains untuk siswa SMA.

Pada tahap define meliputi lima langkah pokok yaitu, (1) Analisis ujung depan, bertujuan untuk memunculkan dan menetapkan masalah dasar yang dihadapi guru dan siswa dalam pembelajaran kimia. Tahap ini dilakukan melalui wawancara dengan guru dan siswa; (2) Analisis Siswa, bertujuan untuk mengetahui karkteristik peserta didik yang meliputi kemampuan akademik, motivasi belajar, psikomotor maupun usia peserta didik. Analisis ini dilakukan dengan memberikan angket kepada peserta didik; (3) Analisis tugas adalah kumpulan prosedur untuk menentukan isi dalam satuan pembelajaran, analisis tugas dilakukan untuk merinci isi materi ajar dalam bentuk garis besar. Analisis ini berupa analisis Kompetensi Dasar (KD) dari materi laju reaksi dan merumuskan indikator pembelajaran; (4) Analisis konsep merupakan identifikasi konsep-konsep utama pada materi yang akan dibahas. Konsep utama yang dibahas adalah materi laju reaksi, persamaan laju reaksi, orde reaksi, konstanta laju reaksi (tetapan laju reaksi), serta faktor-faktor yang mempengaruhi laju reaksi; (5) Analisis tujuan pembelajaran, merupakan pengubahan hasil analisis tugas dan analisis konsep kedalam tujuan pembelajaran. Analisis ini dijadikan dasar untuk mengkonstruksi Modul yang akan dikembangkan.

Tahap design (perancangan) bertujuan untuk merancang bahan ajar dalam bentuk modul berbasis guided imquiry terintegrasi eksperimen pada materi laju reaksi. Rancangan bahan ajar itu didasarkan pada KD dan materi pelajaran sesuai kurikulum 2013. Tahap perancangan meliputi: (a) mempelajari kompetensi dasar, merumuskan indikator pembelajaran dan tujuan pembelajaran yang akan dicapai siswa pada materi laju reaksi, (b) menentukan konsep-konsep sesuai dengan materi laju reaksi, (c) merancang bahan ajar dengan menggunakan siklus pembelajaran guided imquiry yaitu orientasi, eksplorasi, pembentukan konsep, aplikasi dan penutup. (d) pemilihan format yang sesuai dengan format penulisan modul dalam buku panduan pengembangan bahan ajar dari Suryosubroto (1983) tentang sistem pengajaran dengan modul. Format yang dimaksud dalam hal ini adalah tampilan, sistematika penyajian materi, dan isi bahan ajar.

Instrumen pengumpulan data yang diguna kan untuk menentukan tingkat validitas dan praktikalitas modul laju reaksi berbasis guided inquiry terintegrasi eksperimen dan keterampil an proses sains adalah angket validasi dan praktikalitas respon siswa dan respon guru. Data dari angket validitas dan praktikalitas dianalisis menggunakan formula kappa cohen. Kepraktis an dari pengisian lembaran kegiatan dan lembaran kerja pada modul dianalisis dengan teknik persentase. Kategori keputusan nilai momen kappa dapat dilihat pada Tabel 1

$$
\text { momentkappa }(k)=\frac{\rho-\rho e}{1-\rho e}
$$

Tabel.1 Kategori Keputusan Berdasarkan Momen Kappa (k)

\begin{tabular}{|c|c|}
\hline Interval & Kategori \\
\hline $0,81-1,00$ & Sangat tinggi \\
\hline $0,61-0,80$ & Tinggi \\
\hline $0,41-0,60$ & Sedang \\
\hline $0,21-0,40$ & Rendah \\
\hline $0,01-0,20$ & Sangat rendah \\
\hline$<0,00$ & Tidak valid \\
\hline
\end{tabular}

(Boslaugh. Sarah dan Paul A. W. 2008)

\section{HASIL DAN PEMBAHASAN}

\section{Hasil Penelitian}


Telah dihasilkan modul laju reaksi berbasis guided inquiry terintegrasi eksperimen dan keterampilan proses sains melalui model pengembangan four $-D$. Berikut adalah hasil yang didapatkan selama proses penelitian berlangsung:

1. Tahap define (pendefenisian)

a. Analisis Ujung Depan

Berdasarkan hasil wawancara dan angket yag diberikan kepada guru dan siswa dapat disimpulkan bahwa belum terdapatnya bahan ajar yang mengintegrasikan kegiatan eksperimen dengan pembelajaran teori. Bahan ajar yang digunakan belum membuat siswa menemukan konsep sendiri sehingga pembelajaran cenderung menuntut siswa untuk menghitung bukan memahami konsep, kegiatan eksperimen dilaksanakan diakhir pembelajaran hanya untuk mengkonfirmasi konsep dan bahan ajar yang digunakan belum menarik perhatian dan minat siswa untuk belajar. Untuk itu perlu dikembangkan bahan ajar yang dapat memotivasi siswa untuk belajar dan dapat membantu siswa dalam menemukan konsep sendiri.

b. Analisis siswa

Berdasarkan hasil angket siswa, model pembelajaran guided inquiry cocok digunakan pada proses pembelajaran di SMA. Berdasarkan teori perkembangan kognitif Piaget, usia SMA (11-15 tahun) termasuk kedalam tahap operasional formal. Pada tahap operasional formal seseorang memiliki kemampuan berfikir abstrak dan murni simbolis. Hal ini dapat dijadikan pertimbangkan dalam megembangkan modul berbasis guided inquiry terintegrasi eksperimen dan keterampilan proses sains.

c. Analisis tugas

Analisis Kompetensi Inti (KI) dan Kompetensi Dasar (KD) berdasarkan silabus mata pelajaran kimia Kurikulum 2013 karakteristik materi Laju Reaksi dapat dijabarkan sebagai berikut:

3.6.Memahami teori tumbukan (tabrakan) untuk menjelaskan reaksi kimia.

\subsection{Menganalisis faktor-faktor yang mempengaruhi laju reaksi dan menentukan orde reaksi berdasarkan data hasilpercobaan}

4.6.Menyajikan hasil pemahaman terhadap teori tumbukan untuk menjelaskan reaksi kimia.

4.7.Merancang, melakukan, dan menyimpulkan serta menyajikan hasil percobaan faktor-faktor yang mempengaruhi laju reaksi dan orde reaksi.

Berdasarkan KD, maka dijabarkan beberapa indikator pembelajaran sebagai berikut, (1) Menjelaskan konsep laju reaksi; (2) Menuliskan ungkapan laju reaksi; (3) Menjelaskan terjadinya teori tumbukan; (4) Menganalisis hubungan teori tumbukan dengan faktor-faktor yang mempengaruhi laju reaksi; (5) Menentukan orde reaksi; (6) Menentukan persamaan laju reaksi; (7) Melakukan percobaan faktor-faktor yang mempengaruhi laju reaksi

d. Analisis Konsep

Analisis konsep merupakan identifikasi konsep-konsep utama pada materi laju reaksi yang akan dibahas Konsep utama pada materi laju reaksi adalah laju reaksi, hukum laju, tetapan laju, konsentrasi, luas permukaan bidang sentuh, suhu, katalis, tumbukan efektif, energi aktivasi, orde reaksi, reaksi orde nol, reaksi orde satu, reaksi orde dua.

e. Analisis tujuan pembelajaran

Berdasarkan indikator yang telah didapatkan, dapat ditentukan tujuan pembelajaran sebagai berikut, (1) Melalui diskusi kelompok siswa dapat menjelaskan konsep laju reaksi yang disajikan dengan gambar; (2) Melalui diskusi kelompok siswa dapat menulis ungkapan laju reaksi; (4) Melalui diskusi kelompok siswa dapat menganalisis teori tumbukan dan hubungannya dengan laju reaksi dengan tepat dan benar; (5) Melalui data hasil percobaan siswa dapat menentukan orde reaksi dengan benar; (6) Melalui data hasil percobaan siswa dapat menentukan persamaan laju reaksi dengan benar; (7) Melalui percobaan siswa dapat menjelaskan pengaruh konsentrasi terhadap laju reaksi; (8) Melalui percobaan siswa dapat menjelaskan pengaruh luas permukaan terhadap laju reaksi; (9) Melalui percobaan siswa dapat menjelaskan pengaruh suhu terhadap laju reaksi; (10) Melalui percobaan 
siswa dapat menjelaskan pengaruh katalis terhadap laju reaksi

\section{Tahap design (perancangan)}

Gambaran umum tentang modul laju reaksi berbasis guided inquiry terintegrasi eksperimen dan keterampilan proses sains siswa sebagai berikut: (a) cover modul, (b) karakteristik modul, (c) judul/identitas, (d) kompetensi yang akan dicapai, (e) perancangan lembaran kegiatan menggunakan tahapan guided inquiry, (f) perancangan lembaran kerja pada modul, (g) perancangan lembaran tes pada modul.

\section{Tahap develop (pengembangan)}

Berdasarkan hasil analisis per aspek tingkat validitas dari kelima validator dapat dilihat pada Grafik 1.

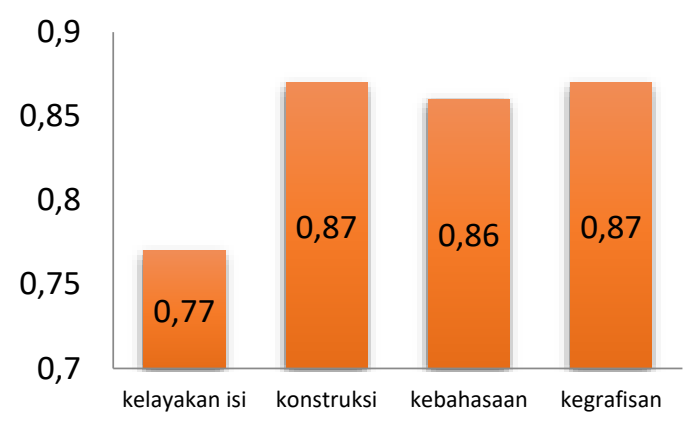

\section{Grafik 1. Rata-Rata nilai momen kappa} Per Aspek

Berdasarkan Grafik 1, diperoleh rata-rata momen kappa terhadap keempat aspek penilaian sebesar 0,84 dengan kategori kevalidan sangat tinggi. Analisis data kepraktisan ada pada Grafik 2.

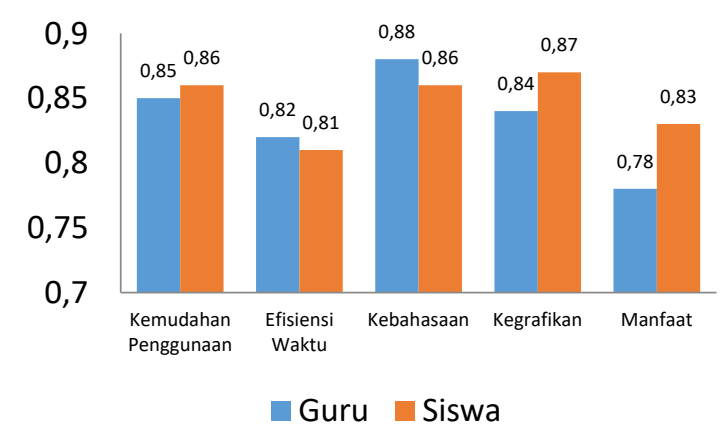

Grafik 2. Rata-Rata Momen Kappa Praktikalitas dari Guru Dan Siswa
Dari Grafik 2 rata-rata momen kappa respon guru dari kelima aspek sebesar 0,83 dan dari siswa sebesar 0,85 dengan kategori kepraktisan sangat tinggi.

Hasil analisis modul yang dikerjakan oleh siswa dalam menjawab pertanyaan kritis, prelab, postlab, latihan dan lembaran kerja siswa dapat dilihat pada Grafik 3

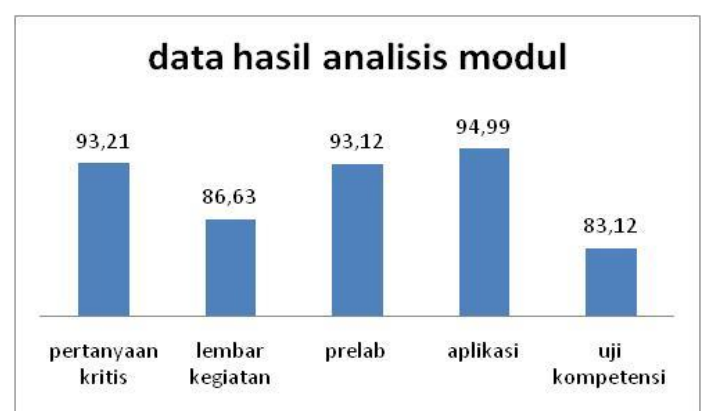

Grafik 3. Data Nilai Rata-rata Siswa menjawab Pertanyaan Kritis, Prelab, Postlab, Latihan dan Lembaran Kerja Siswa

\section{Pembahasan}

1. Uji validitas

Dari aspek kelayakan isi modul, nilai ratarata momen kappa $(0,77)$ dengan kategori kevalidan tinggi. Hal ini menunjukkan bahwa isi modul tersebut telah sesuai dengan KD 3.6, 3.7 4.6, 4.7. selain itu, substansi materi pada modul tersebut sesuai dengan karakteristik materi laju reaksi. Pertanyaan kritis yang dibuat dapat mengarahkan peserta didik dalam pencapaian indikator. Hal ini sesuai dengan fungsi pertanyaan kritis (critical thingking question) dalam pembelajaran guided inquiry yaitu pertanyaan yang dapat membimbing siswa dalam mengeksplorasi model (Hanson, 2006).

Dengan mengintegrasikan eksperimen dan keterampilan proses sains pada modul dapat membantu pemahaman konsep siswa. Pembelajaran yang diintegrasikan dengan eksperimen akan meningkatkan hasil belajar, motivasi belajar dan melatih kemampuan keterampilan proses sains siswa SMA (Andromeda, 2015; Sodikun, 2015)

Dari segi komponen penyajian modul memiliki rata-rata momen kappa 0,87 dengan kategori kevalidan sangat tinggi. Hal ini menunjukkan bahwa modul sudah sistematis dan disusun berdasarkan sintak pembelajaran guided inquiry. Langkah-langkah pembelajaran guided inquiry meliputi orientasi, eksplorasi, pembentukan konsep, aplikasi dan penutup 
(Hanson, 2005). Komponen modul juga sudah sesuai dengan komponen modul menurut Suryosubroto (1983) yang terdiri dari: pedoman guru, lembaran kegiatan siswa, lembar kerja, kunci lembaran kerja, lembaran tes, dan kunci lembaran tes

Komponen kebahasaan, mempunyai kategori sangat tinggi $(0,86)$ Hal ini menunjukkan bahwa modul sudah komunikatif, menggunakan bahasa baik dan benar sesuai dengan kaedah tata bahasa indonesia yang mudah dipahami. Kalimat yang digunakan sederhana sehingga informasi yang disampaikan jelas (Depdiknas, 2008).

Dari segi kegrafisan nilai rata-rata momen kappa 0,87 dengan kategori kevalidan sangat tinggi. Hal ini menunjukkan bahwa modul memiliki jenis dan ukuran huruf yang digunakan tepat dan jelas terbaca, tata letak teratur serta warna yang digunakan dapat menarik perhatian siswa. Instruksi dan informasi yang ditampilkan harus mampu membantu siswa dalam memahami isi modul (Depdiknas, 2008).

Data hasil uji validitas modul laju reaksi berbasis guided inquiry terintegrasi eksperimen dan keterampilan proses sains secara keseluruhan keseluruhan telah dinyatakan valid dengan kategori kevalidan sangat tinggi rata-rata momen kappa sebesar 0,84, namun masih ada beberapa perbaikan untuk uji pada skala yang lebih luas.

\section{Uji Praktikalitas}

Suatu bahan ajar dikatakan praktis jika bahan ajar tersebut dapat dengan mudah digunakan dalam pembelajaran (Mudjijo, 1995).

Berdasarkan analisis data menunjukkan bahwa modul laju reaksi berbasis guided inquiry terintegrasi eksperimen dan keterampilan proses sains dari angket respon guru $(0,85)$ dan respon siswa $(0,86)$ dengan kategori kepraktisan sangat tinggi. Hasil ini menunjukkan bahwa petunjuk penggunaan modul, materi, bahasa, pertanyaan kritis, huruf dan langkah pembelajaran secara keseluruhan dapat memudahkan siswa dalam menemukan konsep.

Penilaian efisiensi waktu pembelajaran, rata- rata momen kappa dari angket respon guru $(0,82)$ dan angket respon siswa $(0,81)$ dengan kategori sangat tinggi. Hasil ini menunjukkan dari aspek efisiensi waktu pembelajaran modul laju reaksi berbasis guided inquiry terintegrasi eksperimen dan keterampilan proses sains yang dihasilkan telah praktis, siswa dapat belajar sesuai dengan kecepatan belajarnya sedangkan guru dapat menyampaikan pembelajaran dengan waktu yang lebih efisien.

Penilaian kebahasaan, rata-rata momen kappa dari angket respon guru $(0,88)$ dan angket respon siswa $(0,86)$ dengan kategori sangat tinggi. Hasil ini menunjukkan bahwa modul laju reaksi berbasis guided inquiry terintegrasi eksperimen dan keterampilan proses sains yang dikembangkan telah menggunakan bahasa yang komunikatif dan dapat membantu siswa dalam menemukan suatu konsep. Modul harus menggunakan bahasa yang jelas dan komunikatif (Daryanto, 2014).

Penilaian kegrafikan, rata-rata momen kappa dari angket respon guru $(0,84)$ dan angket respon siswa $(0,87)$ dengan kategori sangat tinggi. Hasil ini menunjukkan bahwa modul laju reaksi berbasis guided inquiry terintegrasi eksperimen dan keterampilan proses sains yang dihasilkan telah sangat praktis karena huruf, gambar yang digunakan jelas dan mudah dibaca. Tata letak layout teratur dan tampilan modul menarik bagi siswa sehingga dapat menarik minat siswa untuk belajar.

Penilaian manfaat, rata-rata momen kappa dari angket respon guru $(0,78)$ dengan kategori tinggi dan angket respon siswa $(0,83)$ dengan kategori sangat tinggi. Berdasarkan rata-rata nilai momen kappa dari aspek manfaat menunjukkan bahwa modul laju reaksi berbasis guided inquiry terintegrasi eksperimen dan keterampilan proses sains yang dihasilkan telah praktis, dari segi manfaat. Modul dapat membantu siswa memahami konsep dengan baik, menemukan konsep secara mandiri dan dapat meningkatkan keterampilan proses sains siswa.

Hal ini dibuktikan dengan hasil analisis jawaban siswa terhadap modul yang dikembangkan sudah diatas nilai KKM (80). Nilai rata-rata siswa $(90,2)$ dalam menjawab pertanyaan-pertanyaan pada modul (pertanyaan kritis, latihan, pre-lab,post-lab, dan lembaran kerja siswa)

Berdasarkan hasil dari pengolahan data diperoleh rata-rata keseluruahan aspek untuk uji praktikalitas guru sebesar 0,83 dan rata-rata keseluruhan aspek untuk uji praktikalitas siswa sebesar 0,85 dengan masing masing kategori kepraktisan sangat tinggi.

\section{Simpulan}

\section{KESIMPULAN}


Berdasarkan penelitian yang telah dilakukan, dapat disimpulkan bahwa telah dihasilkan modul laju reaksi berbasis guided inquiry terintegrasi eksperimen dan keterampilan proses sains yang valid dan praktis digunakan dalam pembelajaran kimia di SMA

\section{Saran}

Berdasarkan penelitian yang telah dilakukan, maka penulis menyarankan beberapa hal sebagai berikut :

1. Bagi guru yang menggunakan bahan ajar berbasis guided inquiry pada materi laju reaksi ini untuk kegiatan laboratorium pertanyaan pre lab sebaiknya diisi terlebih dahulu dirumah. Sehingga siswa menjadi terarah dalam melakukan eksperimen

2. Bagi guru diharapkan modul laju reaksi berbasis guided inquiry terintegrasi eksperimen ini dapat menjadi salah satu alternatif bahan ajar dalam proses pembelajaran.

3. Bagi siswa yang menggunakan bahan ajar berbasis guided inquiry terintegrasi eksperimen ini diharapkan menyelidiki model yang disajikan agar dapat menjawab pertanyaan-pertanyaan yang ada dalam bahan ajar dan memudahkan dalam menemukan konsep dari materi pelajaran.

4. Untuk penelitian selanjutnya, modul laju reaksi berbasis guided inquiry terintegrasi eksperimen yang dihasilkan diharapkan dapat dilakukan pengujian efektifitasnya.

\section{DAFTAR PUSTAKA}

Andromeda, Bahrizal, Zahara A., (2016). Efektifitas Kegiatan Praktikum Terintegrasi Dalam Pembelajaran Pada Materi Kesetimbangan Kimia Kelas XI SMA/MA. Jurnal Eksakta, Vol 1(1) Mei 2016. index.php/eksakta/article/view/ $6101 / 4738$

Andromeda, Bayharti, Mentari Deliputri, (2015). The Development of Guided Inquiry Based Worksheet for Laboratory Work on Topic of Colloidal System for Senior High School. Prosiding ICOMSET ISBN. 978-602-19877-3-5.P. 273-277

Andromeda, Ellizar, Iryani, Guspatni, Lidia Fitri (2018) Validity and Practicality of Colloid Chemistry Module Based Guided Inquiry Integrated Experiments to Improve the
Science Process Skills of High School Students. IOP Conf. Ser.: Mater. Sci. Eng. 335 012099 doi: 10.1088/1757/899X/335/1/012099

Andromeda, Iryani, Mawardi, Rahmi Susmiati, (2014) Pengembangan Bahan Ajar Berbasis Guided-Inquiry Dengan Representasi Chemistry-Triangle Pada Materi Struktur Atom Untuk Siswa SMA Prosiding ISBN 978-602-70491-09, SEMIRATA2014. http://repository. unp.ac.id/575/1/Prosiding\%20Semirata\%20IPB.pdf

Andromeda, Yerimadesi, Iwefriani, (2017) Pengembangan Lembaran Kerja Siswa (LKS) Eksperimen Berbasis Guided Inquiry Materi Laju Reaksi Untuk Siswa SMA/MA. Jurnal Eksakta Pendidikan.Vol 1(1)Mei 2017, e-ISSN 2579-860X, http://jep.ppj.unp.ac.id/ index.php/jep/article/view/47/23

Boslaugh. Sarah dan Paul A. W. (2008). Statistics in a Nutshell. a desktop quick reference. Beijing. Cambaridge. Famham. Koln. Sebastopol. Taipei.tokyo: o reilly.

Carin, A., (1997). Teaching Science Through Discovery, $8^{\text {th }}$ edition. Ohio: Merrill Publ.co

Chang R., (2010). Chemistry, 10th Edition, McGraw-Hill Companies inc 1221 Avenue of The Americas, NY,

Daryanto. (2014). Pengembangan Perangkat Pembelajaran (Silabus, RPP, PHB, Bahan Ajar) . Yogyakarta: Gava Media

Depdiknas.(2008). Panduan Pengembangan Bahan Ajar. Jakarta: Departemen Pendidikan Nasional Direktorat Jendral Manajemen Pendidikan Dasar Dan Menenga. Direktorat Pembinaan Sekolah Menegah Atas.

Hanson, D., (2005). designing process-oriented guided-inquiry activities. In faculty guidedbook: A comprehensive tool for improving faculty performance, ed. S. $\mathrm{H}$. Beyerline and D. K. Apple. Lisle, IL : Pasific Crest

Hanson, D., (2006). Instructur's guided to process-oriented guided-inquiry learning.lisle.II: Pasific Crest

Hofstein, Avi dan Rachel Mamlok-Naaman. (2007). The Laboratory in Science Education. The State of the Art. Chemistry 
Education Research and Practice e journal. 8(2), 105-107

Hofstein, A and Lunetta V.N., (2003). The Laboratory in Science Education: for the 21st century, Science Education Research 22, 28-54

Mardona. (2013). Analisis Keterampilan Proses Sains Siswa SMA kelas XI IPA pada pokok Bahasan Hidrolisis Melalui Metode Eksperimen. Prosiding Seminar Kimia: ISBN 978-602-19421-09.

Mudjijo. (1995). Tes Hasil Belajar. Jakarta: Bumi Aksara

Nworgu L.N., dan Otum V.V. 2013 Effect of Guided Inquiry with analogy Instructional Strategy on Students Acquisition of Science Process Skill. Journal Education and Practic. ISSN 2222-1735(paper). ISSN 2222-288X (online). Vol 4 No.27.

Permendiknas No 59 tahun 2014, tentang standar isi
Permendiknas No 103 tahun 2014, tentang standar isi

Sodikun. (2015). Pengembangan Modul Berbasis Inkuiri Terbimbing Pada Materi Sistem Pencernaan Makanan untuk Meningkatkan Keterampilan Proses Sains. Surakarta: Universitas Sebelas Maret

Suryosubroto,B.(1983). Sistem Pengajaran Dengan Modul. Yogyakarta: PT. Bina Aksara

Tawil M., dan Liliasari. (2014). KeterampilanKeterampilan Sains dan Implementasinya Dalam Pembelajaran IPA. Makassar: Badan Penerbit Universitas Negeri Makassar

The Colladge Board. (2012). AP Chemistry Guided Inquiry Experiment: Applying the Science Practices. Collage Board.

Trianto. (2010). Model pembelajaran terpadu. Jakarta: Bumi Aksara 